\title{
Addendum to: Comparison of Road Traffic Noise Prediction Models: CoRTN, TNM, NMPB, ASJ RTN
}

\author{
Simon de $\operatorname{Lisle}^{1}$ (D)
}

(C) Australian Acoustical Society 2017

\section{Addendum to Acoustics Australia \\ DOI 10.1007/s40857-016-0061-8}

The author would like to add the following comment to the original Technical Note.

For traffic noise prediction, the CoRTN method has been found to successfully predict the traffic noise in a large number of situations in Australia and overseas. The intent of this
Technical Note was to investigate exceptional circumstances which may be at the boundary of the capability for CoRTN and to compare CoRTN predictions with measured values and with predictions from three other methodologies: TNM, NMPB and ASJ RTN. It is only by better understanding the limitations of each methodology that when faced with unusual situations, there is a better understanding of the limitations of the resultant predicted noise levels.

The online version of the original article can be found under doi:10.1007/s40857-016-0061-8.

Simon de Lisle

simon.delisle@arup.com

1 Arup Acoustics, Sydney, Australia 